IZA DP No. 6832

\title{
Rational Students and Resit Exams
}

Peter Kooreman

September 2012 


\title{
Rational Students and Resit Exams
}

\author{
Peter Kooreman \\ Tilburg University \\ and IZA
}

\section{Discussion Paper No. 6832 \\ September 2012}

\author{
IZA \\ P.O. Box 7240 \\ 53072 Bonn \\ Germany \\ Phone: +49-228-3894-0 \\ Fax: +49-228-3894-180 \\ E-mail: iza@iza.org
}

\begin{abstract}
Any opinions expressed here are those of the author(s) and not those of IZA. Research published in this series may include views on policy, but the institute itself takes no institutional policy positions.

The Institute for the Study of Labor (IZA) in Bonn is a local and virtual international research center and a place of communication between science, politics and business. IZA is an independent nonprofit organization supported by Deutsche Post Foundation. The center is associated with the University of Bonn and offers a stimulating research environment through its international network, workshops and conferences, data service, project support, research visits and doctoral program. IZA engages in (i) original and internationally competitive research in all fields of labor economics, (ii) development of policy concepts, and (iii) dissemination of research results and concepts to the interested public.
\end{abstract}

IZA Discussion Papers often represent preliminary work and are circulated to encourage discussion. Citation of such a paper should account for its provisional character. A revised version may be available directly from the author. 
IZA Discussion Paper No. 6832

September 2012

\section{ABSTRACT}

\section{Rational Students and Resit Exams*}

Resit exams - extra opportunities to do an exam in the same academic year - are widely prevalent in European higher education, but uncommon in the US. I present a simple theoretical model to compare rational student behavior in the case of only one exam opportunity versus the case of two exam opportunities. Numerical examples for a wide range of plausible parameter values show that a second exam opportunity increases the ultimate passing probability only slightly, but strongly reduces average total student effort.

JEL Classification: D01, I21

Keywords: frequency of examinations, education production function, rationality

Corresponding author:

Peter Kooreman

Department of Economics

Tilburg University

P.O.B. 90153

5000 LE Tilburg

The Netherlands

E-mail: p.kooreman@uvt.nl 


\section{Introduction}

Resit exams - extra opportunities for all students to do an exam in the same academic year - are widely prevalent in European higher education, but uncommon in the US. This note presents a simple theoretical model to compare student behavior in the case of only one exam opportunity versus the case of two exam opportunities.

Numerical examples with plausible parameter values show that a second exam opportunity increases the ultimate passing probability only slightly, but dramatically reduces expected total student effort. In some cases students who are lucky to pass at the first attempt spend less than one fifth of the time they would have spent with only one exam opportunity.

While the present paper is related to the educational literature on optimal testing procedures and setting educational standards - see e.g. Costrell (1994) and Lazaer (2006) - the economics of resit exams does not seem to have received any attention in the literature $1^{1}$

\section{The model}

Consider the simplest possible model that captures the key issues of interest. A risk neutral rational student needs to decide how much time to spend on preparing for an exam with a binary outcome, pass or fail. The student wishes to maximize the probability of passing, but faces a constant opportunity cost $w$ per unit of time. The student's utility function might be specified as $U=Y+R U_{P}$. Here $Y=w(Z-t)$ is income, with $Z$ denoting total time available, and $t$ time spent preparing for the exam. $R=1$ if the student ultimately passes and 0 otherwise. $U_{P}$ is the utility of passing. $U_{P}$ can be normalized to 1 without loss of generality through redefining the

\footnotetext{
${ }^{1}$ In an empirical study, De Paola and Scoppa (2011) compare the case of two exams that each cover different parts of the course material versus one exam covering the whole course material. In the present note the course material is the same for both exam opportunities.
} 
time unit in which $w$ is expressed.

\subsection{One exam opportunity}

First consider the case with only one exam opportunity. The relationship between the probability of passing, $p$, and the amount of time spent on exam preparation (or simply "effort"), $t$, is specified as

$$
p(t)=\max \left(0, \frac{\alpha+\beta t}{1+\alpha+\beta t}\right)
$$

with $\beta>0$. Specification (1) captures a number of key features and will allow for analytic solutions of the optimization problem. The passing probability is increasing in effort, with decreasing returns. The parameter $\alpha$ can be interpreted as an indicator of exam difficulty. If $\alpha>0$, it is possible to pass without exerting any effort, as in the case of multiple choice exams. If $\alpha<0$, it is impossible to pass without spending at least a minimum amount of time $t_{\min }=-\alpha / \beta$; see figure 1 (dotted line: $\alpha>0$; solid line: $\alpha<0$ ). The case $\alpha<0$ can also be interpreted as a case with fixed costs (monetary or mental) of doing an exam. The parameter $\beta$ reflects the ability of the student, with $\beta$ being larger for a bright student than for a less talented student 2

The optimal effort follows from maximizing $p(t)-w t$. The solution is given by

$$
\tilde{t}=\beta^{-\frac{1}{2}} w^{-\frac{1}{2}}-\alpha \beta^{-1}-\beta^{-1}
$$

with implied passing probability

$$
\tilde{p}=p(\tilde{t})=1-w^{\frac{1}{2}} \beta^{-\frac{1}{2}}
$$

I assume that $w / \beta<1$ and sufficiently small to ensure positive effort and passing probability. Higher ability leads to a higher passing rate, but the

\footnotetext{
${ }^{2}$ It could be argued that both $\alpha$ and $\beta$ reflect both student ability and exam difficulty. For example, if an exam is poorly designed, $\beta$ can be close to 0 even for a bright student. In this note I will not elaborate on this.
} 
effect of ability on effort is ambiguous. High opportunity costs lead to lower effort and a lower passing probability. Note that in this model an easy exam (high $\alpha$ ) lowers student effort to such an extent that the passing probability remains unaffected. Hence, for a group of homogeneous students passing rates are uninformative about exam difficulty.

\subsection{Two exam opportunities}

If there is a second unconditional exam opportunity, the ex ante ultimate passing probability is $P=p_{1}+\left(1-p_{1}\right) p_{2}$, where $p_{1}$ and $p_{2}$ are the passing probabilities at the first and second attempt, respectively.

Optimal effort follows from backward induction. Suppose the student fails the first time. Then he is back in the situation described in the previous subsection, with the only difference being that a time investment equal to $(1-\delta) t_{1}$ has already been done. $\delta$ is a depreciation factor and likely to be larger the longer the time span between the two exam opportunities. Then it follows from (2) that the optimal time spent preparing for the second opportunity, conditional on $\tilde{t}_{1}$, is given by

$$
\tilde{t}_{2}=-(1-\delta) \tilde{t}_{1}+\beta^{-\frac{1}{2}} w^{-\frac{1}{2}}-\alpha \beta^{-1}-\beta^{-1} .
$$

As in (3), the passing probability is

$$
\tilde{p}_{2}=1-w^{\frac{1}{2}} \beta^{-\frac{1}{2}}
$$

Note that if the student fails at the first attempt, the total time spent preparing for both exams, $T=t_{1}+t_{2}$, is exactly the same as the total time spent when there is only one exam, in the absence of depreciation (i.e. $\delta=0$ ).

The optimal time investment for the first attempt follows from maximizing

$$
p_{1}\left(t_{1}\right)+\left(1-p_{1}\left(t_{1}\right)\right) \tilde{p}_{2}-w t_{1}-w\left(T-(1-\delta) t_{1}\right)\left(1-p_{1}\left(t_{1}\right)\right)
$$

with respect to $t_{1}$, where $T=\beta^{-\frac{1}{2}} w^{-\frac{1}{2}}-\alpha \beta^{-1}-\beta^{-1}$. The solution is given by the positive root of a quadratic equation in $t_{1}$. 
For $\delta=0$ (no depreciation), the expressions for the optimal time investment at the first attempt, the passing probability at the first attempt, and the ultimate passing probability are given by

$$
\left\{\begin{array}{l}
\tilde{t}_{1}=2^{\frac{1}{2}} w^{-\frac{1}{4}} \beta^{-\frac{3}{4}}-\alpha \beta^{-1}-\beta^{-1} \\
\tilde{p}_{1}=1-2^{-\frac{1}{2}} w^{\frac{1}{4}} \beta^{-\frac{1}{4}} \\
\tilde{P}=1-2^{-\frac{1}{2}} w^{\frac{3}{4}} \beta^{-\frac{3}{4}}
\end{array}\right.
$$

For $\delta=1$ (full depreciation), the expressions are

$$
\left\{\begin{array}{l}
\tilde{t}_{1}=w^{-\frac{1}{4}} \beta^{-\frac{3}{4}}-\alpha \beta^{-1}-\beta^{-1} \\
\tilde{p}_{1}=1-w^{\frac{1}{4}} \beta^{-\frac{1}{4}} \\
\tilde{P}=1-w^{\frac{3}{4}} \beta^{-\frac{3}{4}}
\end{array}\right.
$$

The analysis shows that a second exam increases the ultimate passing probability $(\tilde{P}>\tilde{p})$. Students who pass at the first attempt spend less time preparing as when there is only one exam opportunity.

\subsection{A numerical illustration}

In the model students are characterized by four parameters, $\alpha, \beta, \delta$, and $w$. For each parameter, I consider two different plausible numerical values and calculate the outcomes of the model for all 16 combinations. The results are presented in table 1.3

The results show that, for a wide range of parameter values, a second exam opportunity increases the ultimate passing probability only slightly $(P / p)$, but dramatically reduces expected student effort $(\bar{T} / t$, with $\bar{T}=$ $\left.p_{1} t_{1}+\left(1-p_{1}\right) T\right)$, in some cases by almost two thirds. Students who are lucky to pass at the first attempt spend only a fraction of the time they would have spent with only one exam opportunity $\left(t_{1} / t\right)$, in some cases less than one fifth.

\footnotetext{
${ }^{3}$ To interpret numerical values of $w$ note that a student is indifferent between passing and $1 / w$ time units (hours) of non-exam activities.
} 


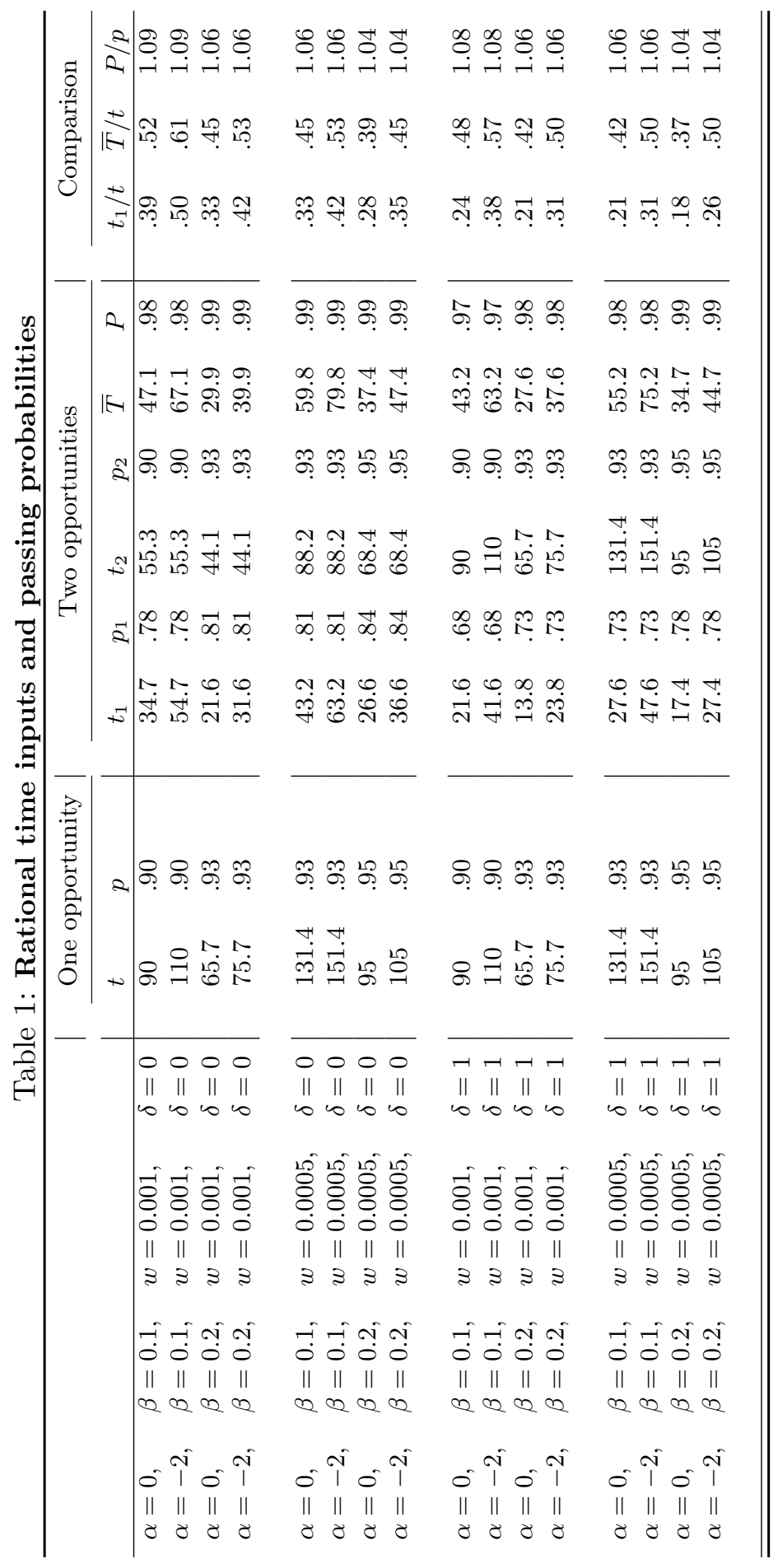




\section{Discussion}

The results presented in this note suggest that unconditionally offering students more than one exam opportunity makes little sense. The main effect is that it provides them with a potential windfall gain of passing at the first attempt with minimal effort. Thus the number of resits can strongly affect student effort and thereby the quality of a degree.

Of course, a number of qualifications should be kept in mind when interpreting the results. For example, the model assumes that students have perfect knowledge about the shape of the relationship between effort and passing probability. In practice, students sometimes use the first exam opportunity to learn about its nature and difficulty. Also, the model assumes that students do not derive any intrinsic utility from exam preparation. Highly motivated and conscientious students might act as if the second exam opportunity does not exist and use it only as a last resort. The numerical results also depend on the degree of randomness in the relationship between effort and passing. A well-designed exam exhibits a steep increase in the passing probability beyond a target effort level. Note however that for parameter values closer to that case $(\alpha=-2 ; \beta=0.2)$ the adverse effects of two exam opportunities still emerge.

Empirical research, preferably based on field experiments, is required to obtain more insight into the benefits and costs of resit exams (including the costs of designing and grading exams for faculty) and the optimal institutional design of evaluating students. 


\section{References}

Costrell, Robert M. (1994), "A Simple Model of Educational Standards", American Economic Review, vol. 84, pp. 956-971.

De Paola, Maria, and Vincenzo Scoppa (2011), "Frequency of examinations and student achievement in a randomized experiment", Economics of Education Review, vol. 30, pp. 1416-1429.

Lazaer, Edward (2006), "Speeding, Terrorism, and Teaching to the Test", Quarterly Journal of Economics, vol. 121, pp. 1029-1061. 
Figure 1: The relationship between time spent and passing probability

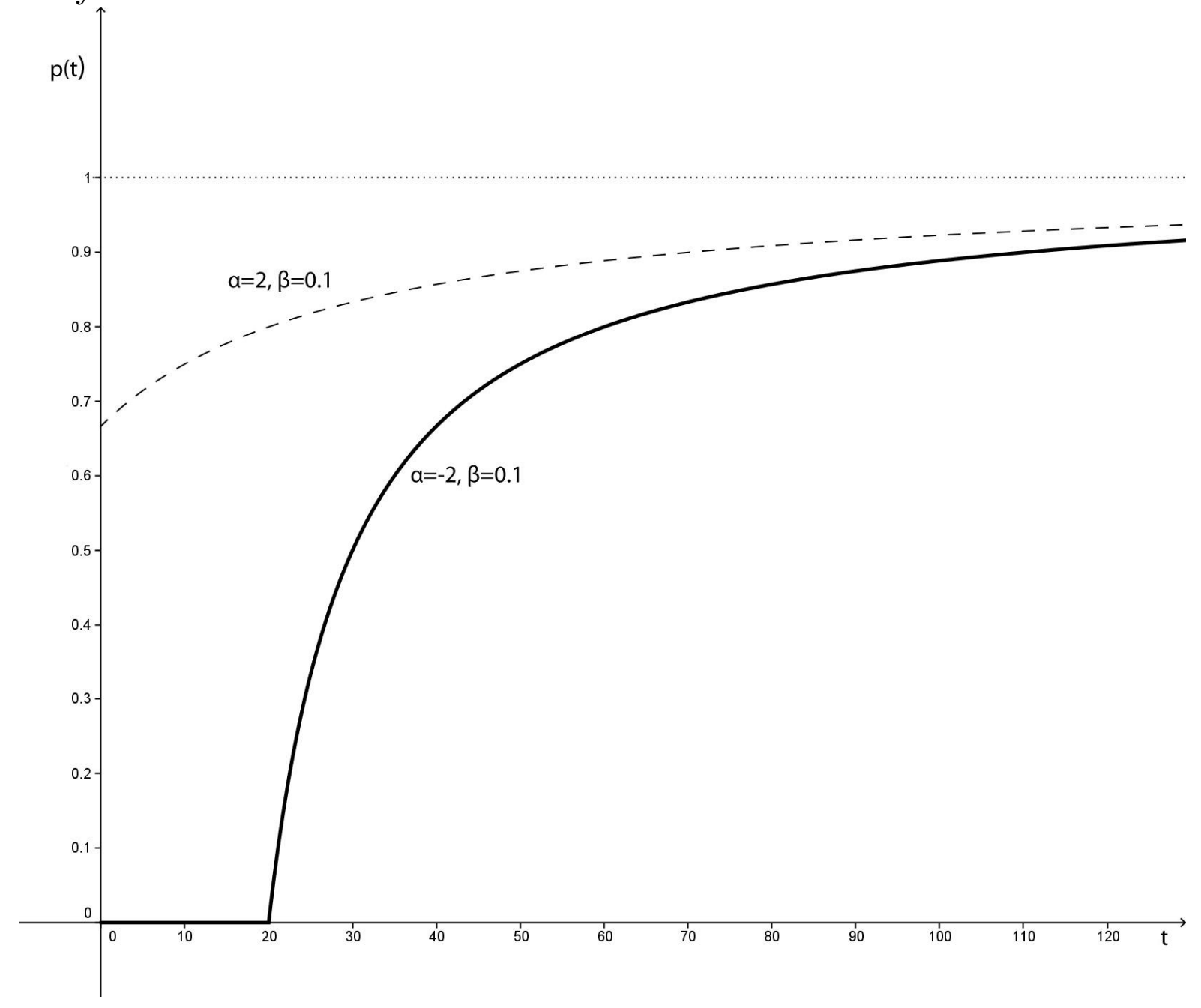

